\title{
Adenomatosis of small intestine: case report
}

\author{
T NAKAMURA, H KIMURA, G NAKANO \\ From the Department of Surgery, Gunma University School of Medicine, Maebashi, Japan
}

SUMMARY A patient complained of severe diarrhoea for about four years. About $2.5 \mathrm{~m}$ of the jejunum was resected and duodenal polyps were also removed at laparotomy. Histologically, they were tubular or tubulovillus adenomas, which closely resembled colonic adenomas. No malignant change was detected in these adenomas. Severe inflammatory changes were seen in the jejunal mucosa and various gut hormones were seen in the same area. As far as we know no similar case with adenomatosis of the small intestine has been reported. We were unable to establish any association between adenomas and severe watery diarrhoea.

Adenomas and adenomatosis commonly develop in the large intestine, but adenomas of the small intestine are rare, ${ }^{12}$ and no case of adenomatosis of the small intestine without adenomatosis in any other part of gastrointestinal tract has been recorded, until recently: three such cases combined with adenomatosis coli have now been reported. ${ }^{3}$ We report here the first case of adenomatosis of the small intestine of unknown origin, accompanied by severe diarrhoea.

\section{Case report}

A 33 year old man with no family history of gastrointestinal disease presented. In October 1976 he had bouts of diarrhoea about five times a day. Although he had been treated, his symptoms had not improved. In December 1977 he suffered a weight loss of $10 \mathrm{~kg}$ and bowel movements increased to about 10 times a day. In May 1980 he was admitted to our department for exploratory laparotomy because a pancreatic tumour was suspected. No evidence of this, however, was obtained with a computed tomography scan or celiac angiography.

At the first operation no pancreatic tumour was detected, but the wall of the small intestine between the ligament of Treitz and a point of $2.5 \mathrm{~m}$ from it had become very thick and somewhat reddened. When the proximal part of the jejunum near the ligament of Treitz was opened we found many polyps. Some were pedunculated with a papillary surface-similar

Accepted for publication 26 March 1986 to a cauliflower in appearance. Some polyps were also observed in the third portion of the duodenum. The upper part of the jejunum (35 $\mathrm{cm}$ in length) was resected (fig 1). Polypectomies of four polyps in the duodenum were also done via the stump of the proximal jejunal remnant.

Even after the operation, however, he had not recovered from diarrhoea. Seven months later another operation was performed to remove all of the remaining jejunum where many polyps had been detected during the first operation (fig 2). His diarrhoea worsened, with about 15 motions a day after the second operation. He died from pneumonia in February 1981.

\section{Pathology}

Macroscopically, the mucosa showed inflammatory changes; the surface was irregular, thickened, slightly raised, and congested from the duodenum to the jejunum. (figs 1 and 2).

Sixty seven polypoid lesions were present in the duodenum and jejunum. The diameter of 29 of the polyps was less than $5 \mathrm{~mm}, 25$ were between $5 \mathrm{~mm}$ and $10 \mathrm{~mm}$, and 13 were more than $10 \mathrm{~mm}$ in diameter (table). The largest polyp was pedunculated and measured $2.5 \mathrm{~cm}$ in diameter (fig 1). Nine of the polyps were sessile, 39 were semipedunculated, and 19 were pedunculated (table). All of the pedunculated polyps measured over $5 \mathrm{~mm}$ in diameter.

Histologically, the polyps were adenomas with mild or moderate dysplasia, similar to those seen in the colon. The adenomas consisted of glands or villus processes lined by tall columnar epithelium, in which 


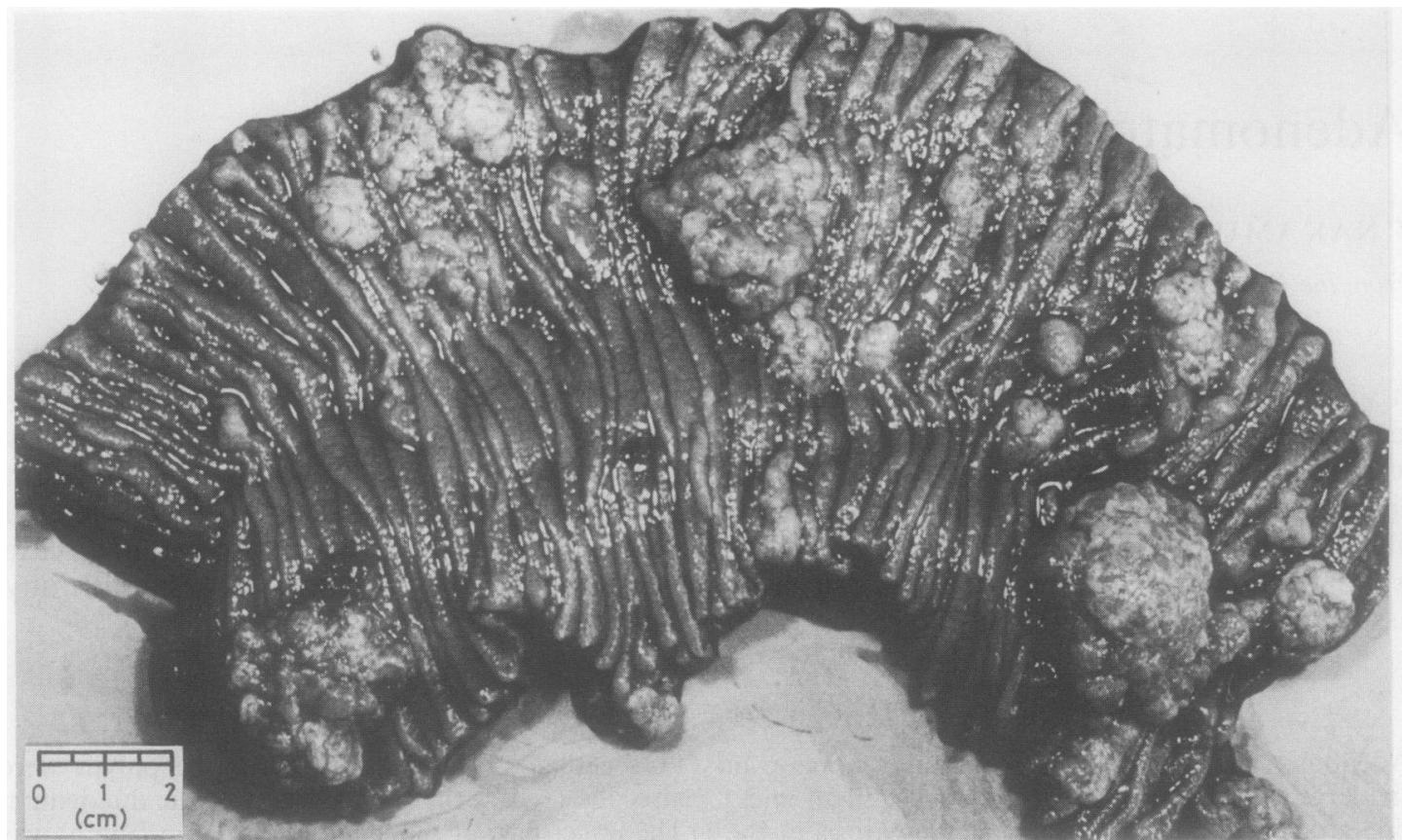

Fig 1 Multiple polypoid lesions at upper jejunum obtained at first operation.

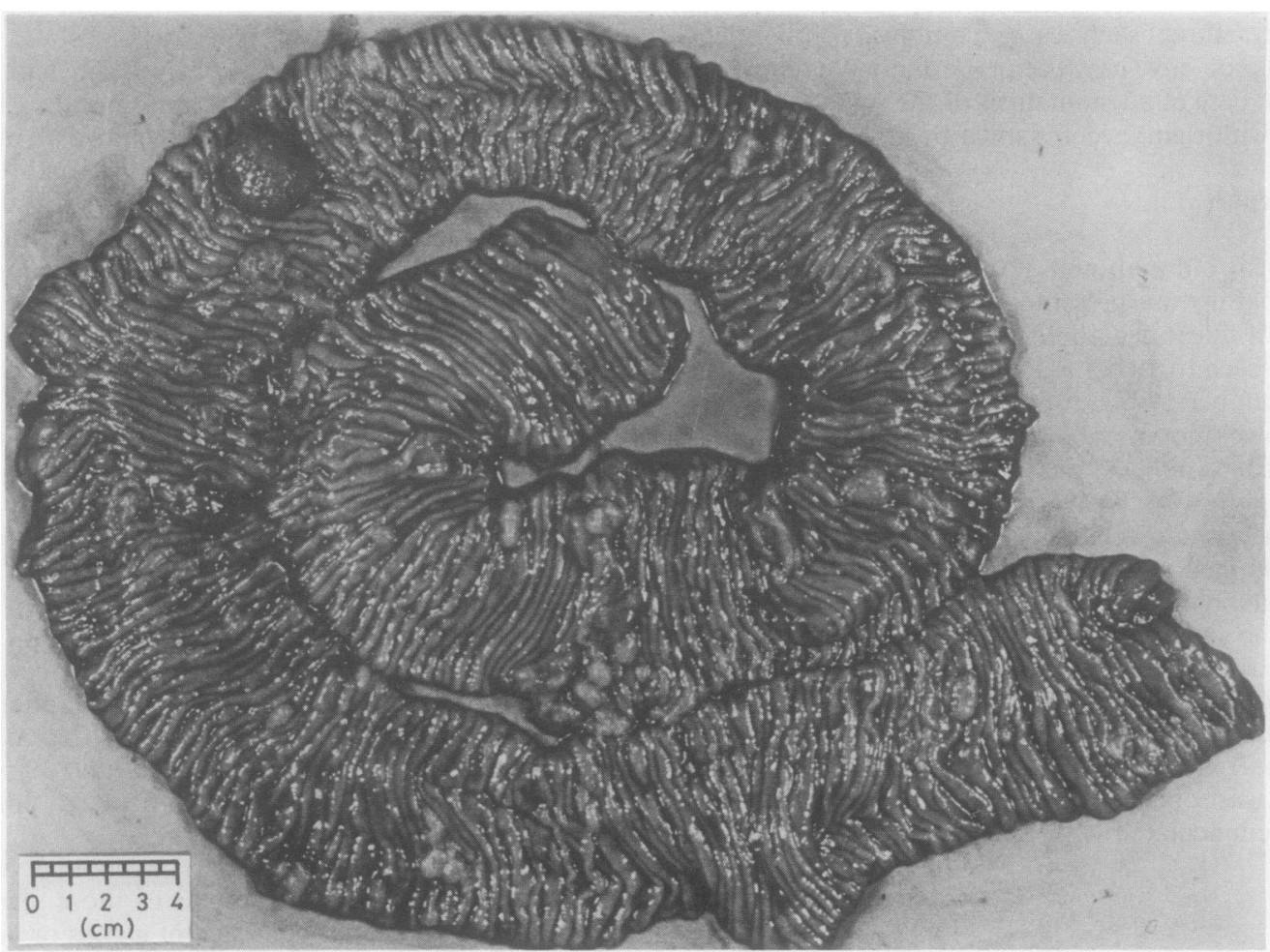

Fig 2 Resected specimen of jejunum showing multiple polypoid lesions obtained at second operation. 
Size of polyps related to shape of stalk

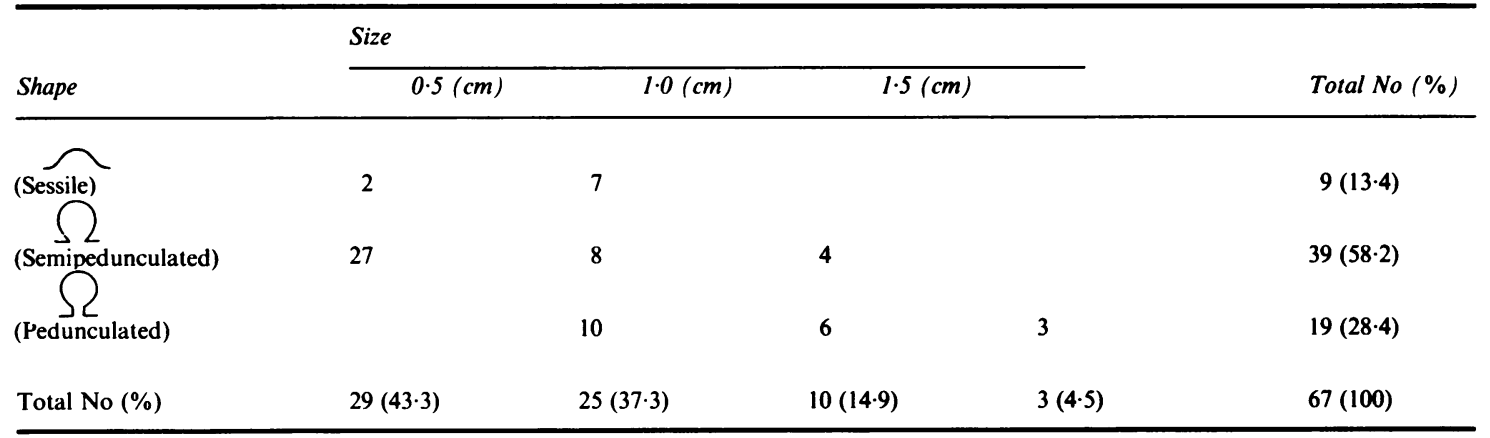

the nuclei appeared oval, elongated, and pleomorphic, with coarse hyperchromatic chromatin granules and prominent nucleoli (figs 3, 4, and 5). Stratification was observed to various degrees, but few nuclei occupied the entire cell. Paneth cells predominated in some adenomas (fig 6). Increased numbers of mitoses were present throughout the tumour, but no focus of cancer (no invasion of the submucosa) was seen in any adenoma.

In the jejunum severe enteritis was observed, with atrophy of glands, proliferation of inflammatory cells such as plasma cells and lymphoid cells, and a high degree of oedema and congestion in the submucosa. Accompanying these inflammatory changes were pseudopolyps scattered among adenomas in the jejunum (figs 7 and 8). The amount of mucus contained in the epithelia of adenomas was less than that found in normal mucosa. The mucosal cells were stained by periodic acid Schiff-alcian blue stain, but not strongly stained by high iron diamine-alcian blue stain.

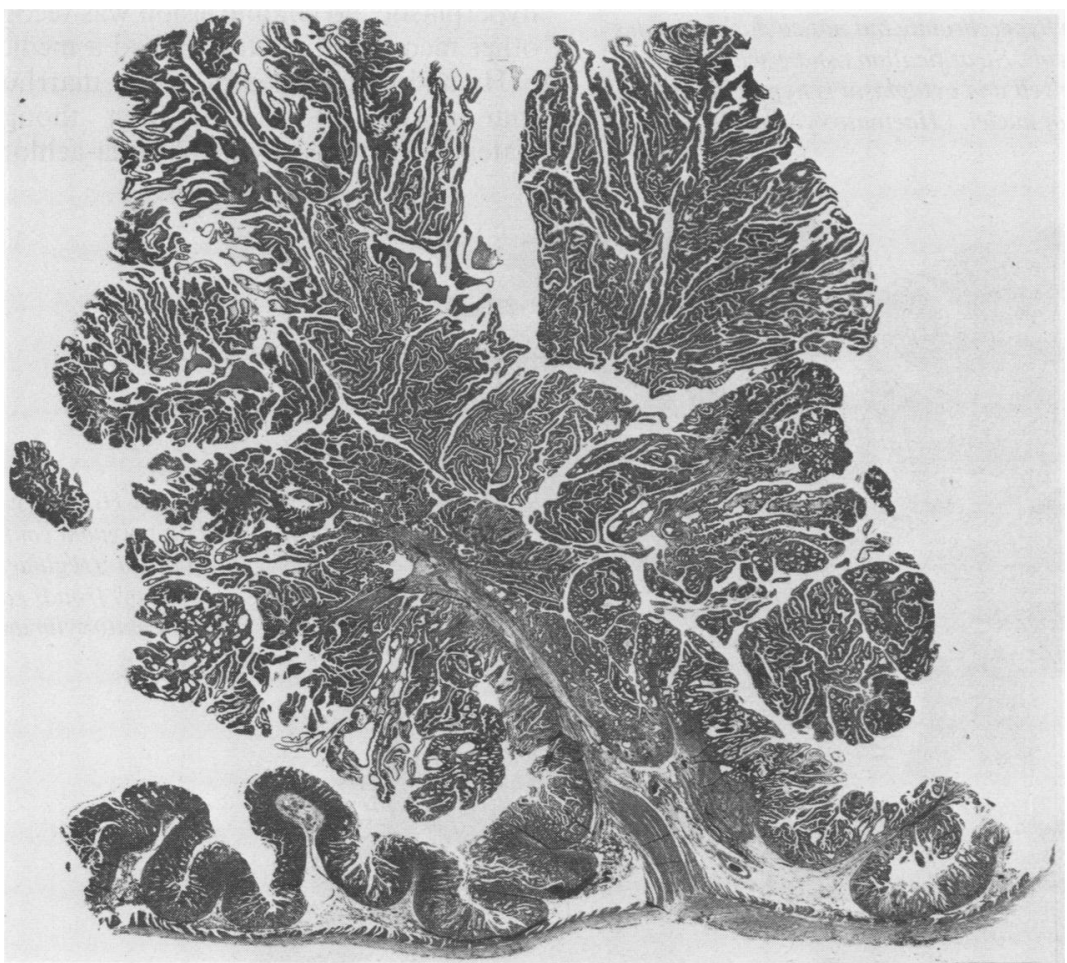

Fig 3 Cross section of adenoma showing polypoid configuration, irregular surface, and many papillary fronds. (Haematoxylin and eosin.) $\times 3.4$. 


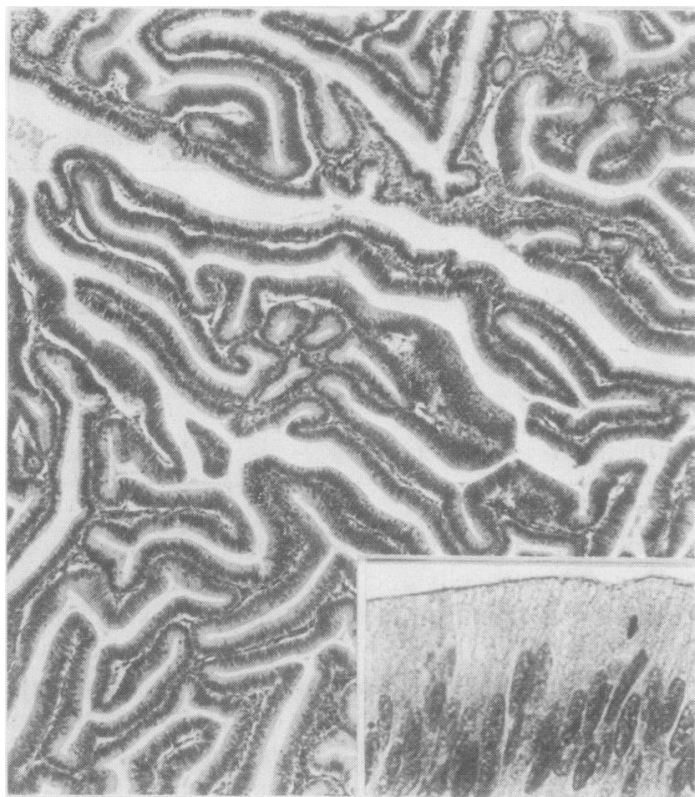

Fig 4 High power view of fig 3 showing papillary formation with epithelial fronds. (Haematoxylin and eosin.) $\times 40$. Inset shows cells of gland duct in upper portion of adenoma. Those cells are closely packed. Nucleus is elongated oval and rounded at end with hyperchromic but not so dark granules and prominent nucleoli. Stratification can be seen but few nuclei occupy entire cell and cytoplasm is hyperchromic but not so dark as that of nuclei. (Haematoxylin and eosin.) $\times 400$.
Using the peroxidase-antiperoxidase stain, gastric inhibitory polypeptide immunoreactive cells were found not only in the mucosal epithelia but also in the mucosa and the submucosa; the nature of the latter cells could not be established (fig 9). Most immunoreactive cells were undetectable in the adenomas.

Electron microscopic photographs of the adenomas showed a few cells that contained secretory granules; a few of these cells were also scattered on adjacent non-neoplastic mucosa. The microvilli of adenoma were shorter than those of normal mucosa and were roughly arranged.

\section{Discussion}

Tumours in the small intestine are relatively uncommon and more than half of them are benign. ${ }^{1-3}$ Although adenomas of the small intestine, usually in the duodenum, have been reported by some authors $^{4-6}$ and a few cases with adenomas of the small intestine have also been reported combined with familial adenomatosis coli, ${ }^{78}$ no case of adenomatosis in the small intestine only has previously been reported.

Our patient also had only two gastric polyps on endoscopic examination, which histologically were hyperplastic; no colonic lesion was recognised and no other member of his family had a medical problem.

He had complained of severe diarrhoea for about four years. He was at first thought to have watery diarrhoea-hypokalaemia-achlorhydria syn=

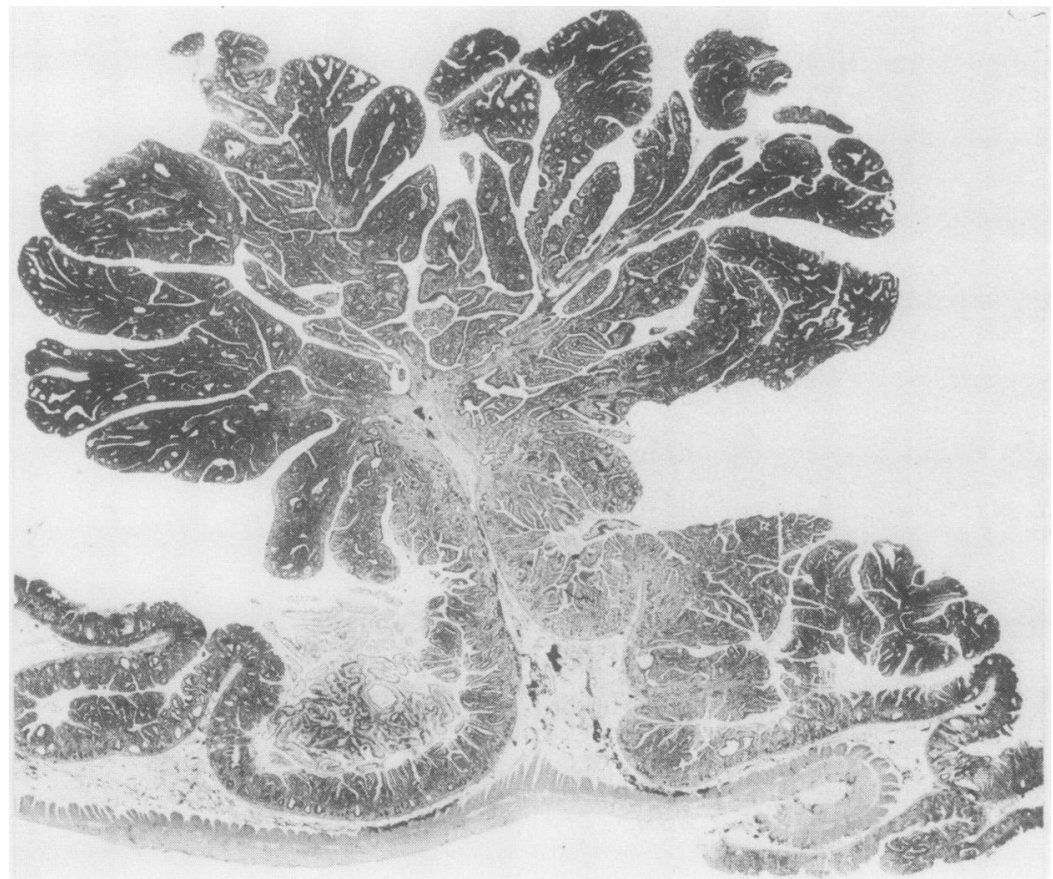

Fig 5 Histology of adenoma with polypoid configuration and manifest irregular surface: a few. papillary fronds can be seen. (Haematoxylin and eosin.) $\times 7 \cdot 1$. 


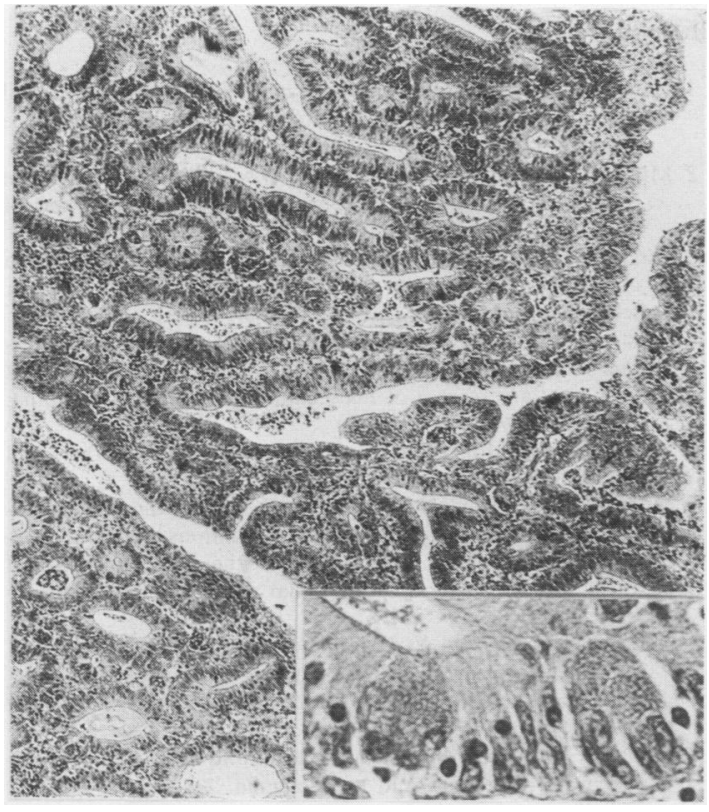

Fig 6 High power view of fig 5 showing tubular adenoma. Glands consist of tall and closely packed epithelial cells. Stratification can be seen, but there is no focus of cancer. (Haematoxylin and eosin.) $\times$ 64. Right inset shows Paneth cells, which can be seen in some areas of this adenoma.

(Haematoxylin and eosin.) $\times 64$.

drome. The immunoreactive vasoreactive intestinal (poly)peptide concentration of the blood in the fasting and postprandial state was not increased, but gastric inhibitory polypeptide was increased. A laparotomy was therefore performed because a gut hormone producing tumour, such as an islet cell tumour, was suspected. The laparatomy failed to show a pancreatic tumour, but multiple polyps were found in the jejunum and duodenum: histologically

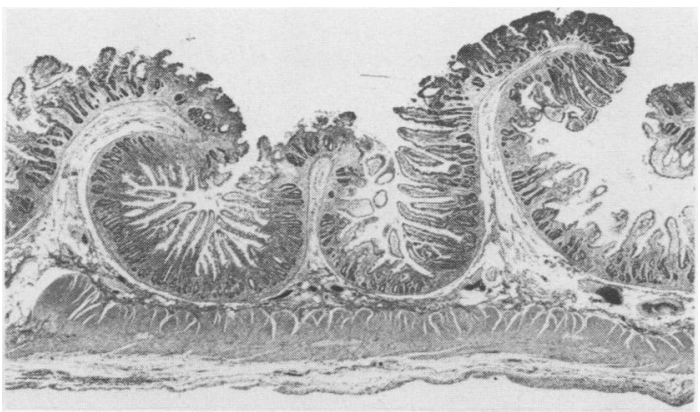

Fig 7 Cross section of resected jejunum. Mucosal surface is irregular, thickened, slightly raised, and congested.

(Haematoxylin and eosin.) $\times 4.5$.

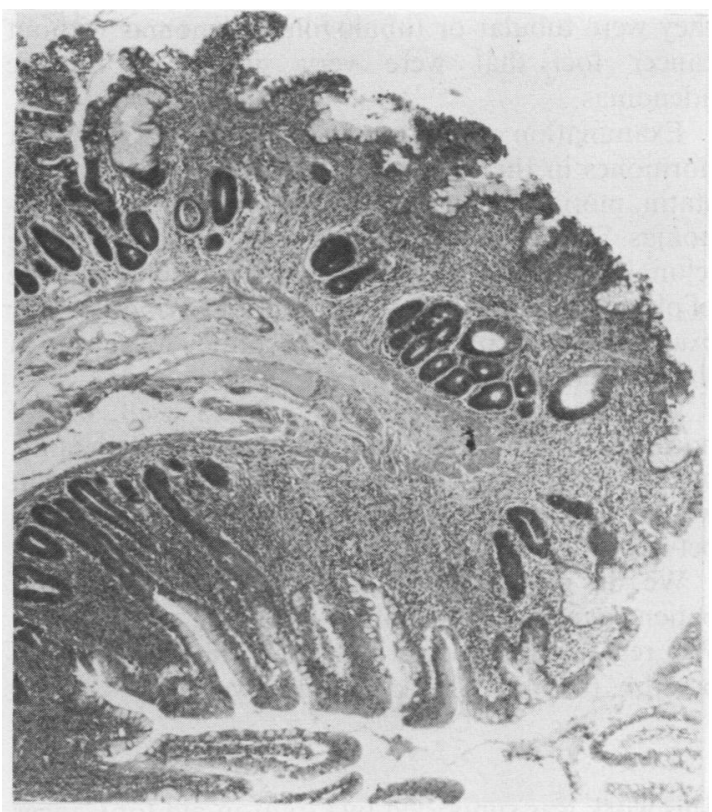

Fig 8 High power view of fig 7 showing severe inflammation with severe atrophy of Lieberkuhn's glands and proliferation of plasma cells in resected jejunal mucosa. (Haematoxylin and eosin.) $\times 40$.

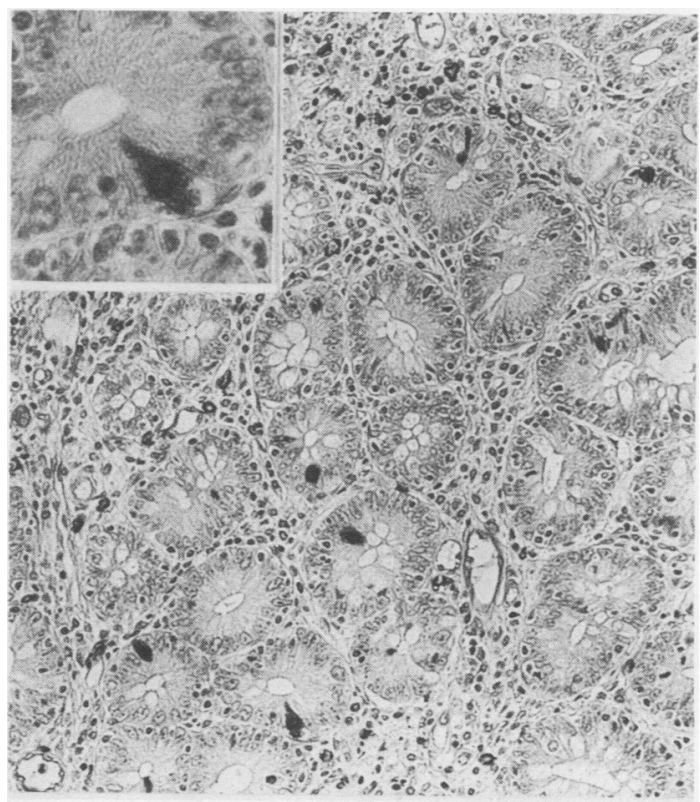

Fig 9 Gastric inhibitory polypeptide immunoreactive granular cells are seen not only in mucosal epithelia, but also in cells of interstitium in mucosa and submucosal space at jejunum. (Immunoperoxidase stain.) $\times 400$. 
they were tubular or tubulovillus adenomas without cancer foci that were very similar to colonic adenomas.

Examination of immunoreactive stains of some gut hormones in the resected specimen showed somatostatin, motilin, and glicentin in a few cells in the adenomas. Severe inflammatory changes were seen in the jejunal mucosa, in which there was a heavy infiltrate of plasma cells (fig 6). A few of the gut hormones-for example, gastric inhibitory polypeptide-were seen in the same area.

It was suspected that the adenoma itself, or gut hormone such as gastric inhibitory polypeptide, might have caused the severe watery diarrhoea, ${ }^{9}$ but we have been unable to establish an association between them.

We do not know of any case, other than our patient, who had adenomatosis of the small bowel. We regard this as an extremely important case, possibly the first of its kind in the world.

This work was supported by Grant-in-aid for Cancer Research from the Ministry of Health and Welfare $(60-35)$ and the Ministry of Education, Science and Culture of Japan (59010091).

\section{References}

1 Heffernon EW, Metcalfe O, Schwarz HJ. Polyposis of the small and large bowel with carcinoma in a villous polyp of the jejunum. Gastroenterology 1962;42:60-2.

2 Mir-Madjlessi S, Farmer RG, Hawk WA. Villous tumors of the duodenum and jejunum. Report of four cases and review of literature. Am J Dig Dis 1973;18:467-76.

3 Perzin KH, Bridge MF. Adenomas of the small intestine: a clinico-pathologic review of 51 cases and a study of their relation to carcinoma. Cancer 1981;48:799-819.

4 Botsford TW, Crowe P, Crocker DW. Tumors of the small intestine. A review of experience with 115 cases including a report of a case: a rare case of malignant hemangio-endothelioma. Am J Surg 1962;103:358-65.

5 Schmutzer KL, Holleran WM, Regan JF. Tumors of the small intestine. Am J Surg 1964;108:270-6.

6 Morson BC, Dawson IMP. Tumours. In: Gastrointestinal pathology. Oxford: Blackwell Scientific Publications, 1979:400-1.

7 Hoffman DC, Goligher JC. Polyposis of the stomach and small intestine in association with familial polyposis coli. $\mathrm{Br} \mathrm{J}$ Surg 1971;58:126-8.

8 Ohsato K, Tsuneyoshi Y, Watanabe H, lida M, Itoh H. Small intestine involvement in familial polyposis diagnosed by operative intestinal fiberoscopy. Report of four cases. Dis Colon Rectum 1977;20:414-20.

9 Verner JV, Morrison AB. Islet cell tumor and a syndrome refractory water diarrhoea and hypokalemia. Am J Med 1958;25: $378-80$.

Requests for reprints to: Professor Takuji Nakamura, Department of Surgery, Gunma University School of Medicine, 3-39-22, Showa-machi, Maebashi 371, Japan. 